\title{
New Year, New Thoughts, New Directions
}

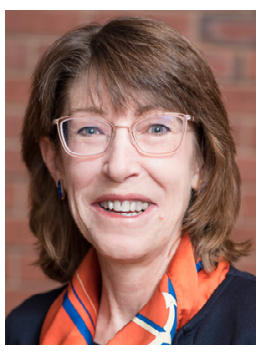

It is an exciting time for JNEB, and this issue is especially great! Exciting for JNEB because we are online only and with a new website! Check us out at www.jneb.org.

I may be prejudiced as the Editor in Chief, and each of our issues is filled with pearls, but this issue, in particular, has particularly impressed me. Our lead article is a SNEB position paper: Healthful Food for Children is the Same as Adults. ${ }^{1}$ Of course it is, you say! Think about this concept, though, and read the paper. Think about it when you babysit your grandkids and try to fix lunch or snacks. Think about when you teach nutrition across the lifecycle or when you see what kids are served in restaurants or on picnics. Think about the implications for food companies and marketing firms. I think that although we all (probably) acknowledge this is true, we may not always act on the concept and don't always promote the policies and practice beyond our specific focus.

A new idea to me was the concept of diet-related self-identity, as described by Ryan et al. ${ }^{2}$ In this article, the authors adapted the 8 dietrelated self-identity constructs of Rosenfeld and Burrow ${ }^{3,4}$ into 4 constructs. Self-reported dietary patterns were also analyzed. Together, these were analyzed to predict diet quality.
Also interesting to me was how Ye et $\mathrm{al}^{5}$ looked at how health communication strategies were received by ethnic groups in China. One was influenced most by mass media, another by family, and the third by village doctors. This analysis lends itself to either using certain strategies with certain groups or broadening communication strategies to include several types in order to ensure widespread acceptance.

We know that dietary diversity is important, but the systematic review by Molani Gol et $\mathrm{al}^{6}$ examined the association of dietary diversity with growth outcomes for infants aged under 2 years and for children under 5. Their results suggest a stronger association with the infant-centered studies (45 studies) and less strong for children under 5 years (36 studies). Examining possible modifiers to dietary diversity is recommended by the authors for future studies.

Finally, I must comment on the Perspective by Bellows et al. ${ }^{7}$ They call on us to sustain our research rigor by acknowledging the complexity of our work, enhancing training, and endeavoring to promote funding of our critical research areas. I hope this article is read widely, and that it influences many to consider their own training, collaborations, and the training of our students.

Karen Chapman-Novakofski, PhD, RDN Editor-in-Chief Journal of Nutrition Education and Behavior, Advancing Research, Practice, and Policy

\section{REFERENCES}

1. Rothpletz-Puglia P, Fredericks L, Dreker MR, Patusco R, Ziegler J. Position paper on kids' food. J Nutr Educ Behav. 2022;54:4-11

2. Ryan JC, Alchin C, Anastasiou K, Hendrie G, Mellish S, Litchfield C. Exploring the intersection between diet and self-identity: a cross-sectional study with Australian adults. $J$ Nutr Educ Behav. 2022;54:20-27.

3. Rosenfeld DL, Burrow AL. The unified model of vegetarian identity: A conceptual framework for understanding plant-based food choices. Appetite. 2017;112:78-95.

4. Rosenfeld DL, Burrow AL. Development and validation of the Dietarian Identity Questionnaire: assessing self perceptions of animal-product consumption. Appetite. 2018;127:182-194.

5. Ye R, Wu Y, Sun C, Wang Q, Mao Y, Raat H, Rozelle S, Johnstone H, Zhou $H$. Health communication patterns and adherence to a micronutrient home fortification program among diverse ethnic groups in rural western China. $J$ Nutr Educ Behav. 2022;54:36-45

6. Molani Gol R, Kheirouri S, Alizadeh M. Association of dietary diversity with growth outcomes in infants and children under 5 years: a systematic review. J Nutr Educ Behav. 2022;54:65-83.

7. Bellows LL, Mena NZ, Reznar MM, Taylor CA, Sigman-Grant M. Strengthening nutrition education and behavior research for academicians and practitioners. $J$ Nutr Educ Behav. 2022;54:84-93. 